achieved by Maiman and soon after by a group at the Bell Telephone Laboratories, again using ruby as the active material. In the latter case the parallel plates were made by grinding optical flats on the ends of a ruby rod about $0.5 \mathrm{~cm}$. in diameter and $4 \mathrm{~cm}$. in length and then coating them with silver.

The emitted light was red and had wave-lengths corresponding to the red fluorescence of ruby. A very intense source of light of much shorter wave-length was used to depopulate the ground-state of the $\mathrm{Cr}^{3+}$ ions, so that originally only short pulses were used. Electrons then fell back into the metastable states (a doublet) from which the fluorescent radiation originates so that these acquired a population in excess of that of the ground state, so producing an emissive condition. A large part of the radiation absorbed as pump-power is re-emitted in all directions through spontaneous emission, only a small fraction going into the coherent radiation in the beam. Nevertheless very high intensities can be produced; for example, a light pulse lasting $0.5 \mathrm{~m}$.sec. and having energy 0.2 joule has been achieved. The beam is only partly coherent due to defects in the ruby but it may be focused to a spot of about $0.1 \mathrm{~mm}$. diameter. The mean output is thus $0.4 \mathrm{~kW}$. and the power flux of the order of $4 \times 10^{6} \mathrm{~W} . / \mathrm{cm} .^{2}$. This should be compared with a value of the order of $500 \mathrm{~W} . / \mathrm{cm} .^{2}$ obtainable by focusing the Sun with an $f 1$ lens. A device of this kind is known as a 'laser' the $l$ standing for light. Many possible uses have been proposed including signalling from the Moon. The most practical use made so far would appear to be in flash photomicrography. If continuous operation could be obtained, and we understand that this has now been achieved with a ruby laser although no details are available, the higher power flux could be used to melt refractory materials.

Lasers may also be made to operate in the near infra-red using $\mathrm{U}^{3+}$ ions in calcium fluoride. In this case the final state for the emission lies a little above the ground-state and can be effectively emptied by cooling the sample with liquid helium. Much less pump power is now required. Continuous operation of a laser has been obtained by Javan et al. using a mixture of hydrogen and helium as the active medium. The parallel plates in this case are placed in the gas. which is excited by a high-frequency discharge, exchange of excitation between the hydrogen and a metastable state of helium producing the emissive condition. The Fabry-Perot plates need to be flat to a very high degree of accuracy and have a multi-layer coating to give high reflectivity and low absorption. This is required because many passages through the gas are needed because of its low density compared with that of the ions in ruby. A much more accurately phase coherent beam is obtained, however, interferometric experiments showing coherence over the whole diameter of the beam, which was about $1.5 \mathrm{~cm}$.

These devices are clearly in an early stage, and many new developments may be expected in the near future. Monochromatic sources in the infra-red will be of the greatest value and intense coherent sources of light open up many possibilities for optical experiments. Already lasers have been used for demonstrating beats between light waves and the generation of harmonies at optical frequencies.

An important new chapter has been started in the study and use of light and radio waves. It is curious how long it has taken in this case to find this new application of theory now more than half a century old.

There was, of course, also quite a gap between the first publication of Maxwell's theory of the electromagnetic field and its practical use in radio communication. These developments in the use of stimulated emission are also likely to lead to exciting new episodes in the story started by Maxwell in King's College, London, about a century ago.

\title{
OBITUARY
}

\section{Prof. F. Richter}

BeIrstein's Handbuch der Organischen Chemie is now in its fourth edition and has been extended by two complete supplements so that with comparatively few exceptions all compounds prepared up to 1929 are included. A third supplement is now appearing. If those who use this great work had time to look back to 1881, when the first edition appeared, they would be conscious of a simpler and less-hurried existence. The devotees of chemical science were few, their laboratories by present-day standards were poorly equipped and the physical aids now so valuable had never been imagined. Nevertheless, thankfulness for the privilege of being a chemist or a student of chemistry and the slow, sometimes painful, but always exciting process of acquiring at the laboratory bench that invaluable 'feel' for organic compounds produced the results and laid the foundations on which the modern edifice of carbon ehemistry has been constructed.

Four names have been specially associated with the development of the Handbuch: Konrad Friedrich Beilstein, Paul Jacobson, Bernhard Prager and Friedrich Richter. At the time of his death on
November 22, 1961, at the age of sixty-five, Richter was director of the Beilstein Institut für Literatur der Organischen Chemie in Frankfurt a/d Main. Since 1933 he had been responsible for the production of Beilstein during the most difficult period of its history and had seen eighty volumes through the press. On many occasions he recorded or lectured on the history of this great undertaking. It is remarkable that long-continued work on a production of this kind should, nevertheless, have given rise to so much loyalty and self-sacrifice, to so much real joy and justifiable pride in achievement and to such deep satisfaction in serving the needs of chemical science. Those who have read Richter's writings on Beilstein-the man and the work-realize that this description of his own outlook and that of his staff and predecessors is not exaggerated.

Friedrich Richter was born in Berlin on September 1, 1896, and educated at the humanistic FriedrichsGymnasium, where he was a remarkably outstanding pupil. At the University of Berlin he first studied classical and semitic philology, but soon decided that his interests lay in natural science. His command of languages dates from this time, however, and he read English, French, Italian, Spanish, modern Greek and 
Russian with ease. His written and spoken English wore of a high order. His teachers in Berlin were Emil Fischer, Leuchs, Traube and also Tiede, with whom he worked on the phosphorescence of magnesium sulphide. It is intoresting that Richter, whose whole life was to be devoted to organic chemistry, should have carried out his first research on such a subject. It may be mentioned, however, that even Ramsay's early researches were concerned with the toluic acids and then with pyridino bases. Richter left Tiede in 1917 and worked for a year with Haber on methods for the analysis and counteraction of 'war gases'. $\mathrm{He}$ also began to abstract papers for the Chemisches Central Blatt and soon afterwards became associated with the production of the first volume of the fourth edition of Beilstein which was published in 1918; his name appears on page xxviii.

Shortly after the death of Paul Jacobson in 1923 the German Chemical Society asked him to undertake the preparation of the first and second Ergänzungs werke which, with the Hauptwerk of the fourth edition, would provide a survey of the literature up to 1929 . Bernhard Prager, who had succeeded Jacobson, retired in 1933 and from that time Richter was responsible for the production of the whole work.

The years that followed were marked by everincreasing difficulties. Many members of his staff were lost owing to the racial policy of the Govern. ment; during the Second World War the Hofmann Haus was destroyed and the editorial office transferred first to Silesia and then to Tharandt in Saxony. It was finally re-established as the Beilstein Institut in Frankfort a/d Main. The next fifteen years, though presenting many problems for Richter and his colleagues, were characterized by steady progress, confidence in tho value of their work and by wide recognition of Richter's outstanding qualities not only as an organizer with a unique knowledge of chemical literature but also as a dodicated scholar and a cultivated man. The success with which he carriod out an almost superhuman labour was largely due to what his brothor, Dr. Hans Richter, has described as his economy of mental effort (geistige Ökonomie). Without this capacity the magnitudo of his task, both in its broad conception and in detail, might have become overwhelming.

In 1956 the University of Frankfurt elected Richter to an honorary professorship, and there, and in the University of Mainz, he lectured on nomenclature and documentation. Heidelberg made him an honorary doctor and the Gesellschaft Deutscher Chemiker awarded him the Gmelin-Beilstein Medal. His lecture on this occasion has been published.

Between 1923 and 1931 Richter found time for research on aspects of terpene chemistry and related topics, in the laboratory of the Hofmann Haus. He studied first the bromination of thymol in glacial acetic acid and showed that one of the products, tribromomenthadienone, readily loses the isopropyl group when treated with sulphuric acid. In later papers he found that unexpected structural changes may occur during the hydrogenation of various unsaturated compounds of the terpene serios. Thus $\beta$-pinene gave $\alpha$-pinene and finally pinane in presence of palladium black. Sabinene under similar conditions suffered fission of the three-membered ring to give an unsaturated and then a saturated dorivative of cyclo-pentane. Hydrogenation with platinum black, however, proceeded normally giving thujane. $\alpha$ - and $\gamma$-terpinene in a nitrogen atmosphere with palladium saturated with hydrogen reacted violently, giving eymene as well as menthene and menthane. This work on terpinene led him directly to a study of the physical properties of eymene and the reactions of ascaridole.

About 1930 Richter's laboratory was dismantled owing to the need of the Hofmann Haus for more library space. For a time he secured accommodation in tho laboratory of Prof. Rosenheim, but after 1932 his publications were confined to articles dealing with stereochemistry, the life of von Baeyer and especially the life and work of Beilstein and the history of his Handbuch.

In 1952 Richter visited the Department of Organic Chemistry in the University of Leeds. A research student had just synthesized the solid isomer of thiophthen and felt greatly honoured that the first chemist from outside the Department to whom he showed his specimen was the head of the Beilstein organization.

Richter was no mean pianist and organist; he was an authority on the art of East Asia, especially on Chinese and Korean ceramics, and steadily refused to allow his heavy professional work to interfere with these interests. His appreciation of Japanese woodcarving led him to study the language, with the result that during the long evenings spent in Silesia he translated a collection of ghost stories from Japanese into both German and Russian. He also utilized his knowledge of Japanese in his professional work.

In spite of Richter's deep knowledge of his chosen science and his wide cultural interests, he was nover pedantic or merely erudite. He was always ready to discuss, with a characteristic clarity, professional, literary or artistic matters and to answer questions. To have solved a problem, whether in discussion or in tho laboratory was to him a source of deep satisfaction. Whenever he learned a new language Richter studied its literature. He loved books, and his library and art collections were a treasure house. Their destruction during the War was a grievous blow to him which he bore without complaint.

Richter's physique was not robust, but ho inherited from his mother a great tenacity of spirit. Moreover, like St. Paul, whoso epistles he and a student translated from the original text, he learnod to come to terms with his physical limitations. He was never married but lived for many years with his brother in ideal understanding. Though always courteous, he was very diffident and reserved and at times may have appeared aloof. Not many people knew him well. This was not due to conceit or to any kind of arrogance on his part but rather to his very independent and restrained judgment of men and things.

On the other hand, he possessed great social gifts and when among congenial people he was a brilliant, polished and, at times, humorous conversationalist, with a light and gracious touch which gavo great pleasure to those who understood him. Richter had a love for southern Europe and its poople, to whom his agile and imaginative nature made him akin. Those for whom he lifted his curtain of reserve and gave of his friondship were permanently onriched by the experience.

I am grateful to Dr. Hans Richter and to Frau R. Knoll for sending me much valuable information about Richter's scientific work and cultural interests and a striking assessment of his character.

Frederick Chatlengen: 